\title{
PERANCANGAN KURSI BONCENG ANAK USIA 1-3 TAHUN UNTUK MOTOR MATIC DENGAN METODE QFD DAN ANTROPOMETRI
}

\author{
Khusna Dwijayanti ${ }^{1}$, Muhammad Choiru Zulfa ${ }^{2}$, Dewi Rohmawati ${ }^{3}$ \\ Teknik Industri Fakultas Sains dan Teknologi UNISNU Jepara \\ khusna.dwijayanti@unisnu.co.id
}

\begin{abstract}
Product design and development aims to improve existing products. The product in this research is a children seat embedded in motorcycle for children age 1 to 3 years. The design of existing child seats is still dangerous for their children due to poor attention to the child safety aspect. The product design begins by identifying the needs of consumers, design using QFD (Quality Function Deployment) method, anthropometric data of the child's body, validity and reliability test of questioner, then design for seat motorcycle that is safe for the children. The design result of the chair for children aged 1 to 3 years based on customer needs is a safety seat for the wearer, comfortable chair for the wearer, economical price, chair frame of rattan and the addition of seat belt so that the child is safer when using the chair. The design result using anthropometry data of child body obtained the backrest height of the seat $30 \mathrm{~cm}$, seat backrest width $26 \mathrm{~cm}$, seat length $24 \mathrm{~cm}$ and seat width $22 \mathrm{~cm}$.
\end{abstract}

Keywords: QFD, designing, motorcycle children seat, anthropometry

\begin{abstract}
ABSTRAK
Perancangan dan pengembangan produk bertujuan untuk memperbaiki produk yang telah ada. Produk yang menjadi rancangan pada penelitian ini adalah kursi bonceng anak usia 1 sampai 3 tahun. Desain kursi anak yang telah ada saat ini masih berbahaya bagi anak mereka karena kurang memperhatikan aspek keselamatan anak. Pembuatan desain produk ini dimulai dengan mengidentifikasi kebutuhan konsumen, perancangan menggunakan metode QFD (Quality Function Deployment), pengolahan data antropometri tubuh anak, uji validitas dan reabilitas terhadap data kuisoner, kemudian dilanjutkan dengan perancangan desain kursi. Hasil perancang dari desain kursi bonceng anak usia 1 sampai 3 tahun berdasarkan customer needs adalah kursi bonceng yang aman bagi pemakai, kursi yang nyaman bagi pemakai, harga ekonomis, pengambilan bahan kerangka berupa rotan dan penambahan sabuk pengaman agar anak lebih aman saat menggunakan kursi tersebut. Hasil perancangan menggunakan data antropometri tubuh anak diperoleh tinggi sandaran kursi memiliki tinggi $30 \mathrm{~cm}$, lebar sandaran kursi $26 \mathrm{~cm}$, panjang dudukan kursi $24 \mathrm{~cm}$ dan lebar dudukan sebesar $22 \mathrm{~cm}$.
\end{abstract}

Kata Kunci: QFD (Quality Function Deployment), perancangan, kursi bonceng anak, antropometri

\section{PENDAHULUAN}

Perancangan dan pengembangan produk adalah semua proses yang berhubungan dengan keberadaan produk yang meliputi segala aktivitas mulai dari identifikasi keinginan konsumen sampai fabrikasi, penjualan dan pengiriman produk (Bayu Chistdiyanto, 2014). Perancangan dan pengembangan produkdiperlukan untuk memperbaiki produk yang telah ada.

Desain kursi anak yang telah berkembang saat ini masih berbahaya bagi anak mereka karena kursi bonceng kurang memperhatikan keselamatan anak. Hal tersebut dapat terjadi ketika para orang tua mengajak anak mereka mengendarai sepeda motor dan tiba-tiba direm mendadak, anak tersebut dapat terbentur yang mengakibatkan cedera selain itu desain kursi bonceng yang ada saat ini masih kurang kurang nyaman saat digunakan.

Kursi bonceng anak merupakan produk yang digunakan para orang tua untuk memudahkan mengajak anak mereka naik motor, tanpa menggendong anak tersebut. Hal ini dilakukan agar para orang tua dapat mengurangi kelelahan saat berkendara karena harus menggendong anak mereka. 

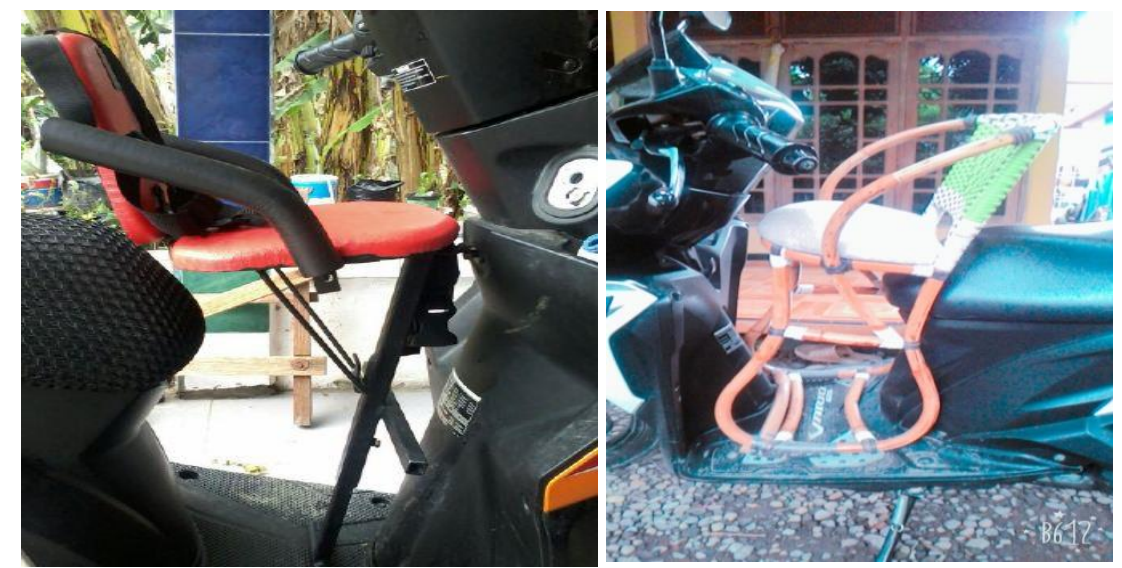

Gambar1. Jenis-jenis kursi bonceng anak

Kursi bonceng biasanya digunakan untuk anak usia 1 sampai 3 tahun, alasanya karena anak yang usianya lebih dari 3 tahun kurang muat untuk menggunakan kursi Selain itu anak yang berusia lebih dari 3 tahun lebih senang berdiri dari pada duduk.

Desain kursi bonceng anak usia 1 sampai 3 tahun selalu mengalami perkembangan seiring dengan berjalanya waktu, yang awalnya hanya untuk sepeda sekarang berkembang untuk sepeda kayuh, khususnya sepeda motor matic. Perkembangan kursi bonceng anak ini sering kali belum memperhatikan ergonomi dan memperhatikan aspek keselamatan bagi anak, karena desain kursi duduk ini sering kali hanya memperhatikan desain yang simpel dan menarik pembeli. Contoh kursi bonceng anak dapat dilihat pada Gambar 1.

Produk yang menjadi rancangan rancangan pada penelitian ini adalah kursi bonceng anak usia 1 sampai 3 tahun untuk sepeda motormatic. Perancangan kursi duduk ini lebih memperhatikan keinginan konsumen dan aspek ergonomi bagi anak.

Dari uraian latar belakang, maka permasalahan di dalam penelitian ini yaitu:
1. Bagaimana merancang dan mengembangkan produk khususnya kursi bonceng anak usia 1 sampai 3 tahun untuk sepeda motor maticsehingga menghasilkan produk yang sesuai keinginan konsumen?

2. Bagaimana menyusun konsep produk yang akan dikembangkan sesuai dengan kebutuhan konsumen?

3. Bagaimana merancang kursi bonceng anak yang sesuai dengan dimensi tubuh anak?

\section{TINJAUAN PUSTAKA}

Quality Function Deployment (QFD) adalah suatu cara untuk meningkatkan kualitas barang atau jasa dengan memahami kebutuhan konsumen kemudian menghubungkanya dengan ketentuan teknis untuk menghasilan suatu barang atau jasa pada setiap tahap pembuatan barang atau jasa yang dihasilkan (Rosnani Ginting, 2013).

Aplikasi QFD difokuskan pada desain produk, produktivitas dan evaluasi terhadap suatu produk.Suatu organisasi yang mengimplementasikan QFD dapat memberikan informasi mengenai produktivitas dan kualitas produk, mengurangi biaya, dan mengurangi waktu pengembangan produk. 
Tujuan QFD adalah memenuhi keinginan konsumen dengan cara merancang produk baru agar dapat berkompetisi dan bersaing dengan produk dari kompetitor. QFD berguna untuk memastikan bahwa suatu perusahaan. QFD. berguna untuk memastikan bahwa suatu perusahaanmemperhatikan kebutuhan konsumen sebelum membuat perancangan produk baru.

Adapun manfaat dari QFD sebagai berikut:

1. Memusatkan rancangan produk dan jasa baru pada kebutuhan pelanggan.

2. Mengutamakan kegiatan-kegiatan desain.

3. Menganalisis kinerja produk.

4. Menurangi banyaknya perubahaan desain setelah dikeluarkan dengan memastikan upaya yang difokuskan pada tahap perencanaan.

5. Menyediakan suatu cara untuk membuat dokumentasi proses dan menyediakan suatu dasar yang kukuh untuk mengambil keputusan.

Focus Group Discussion

Pendekatan focus group discussion memungkinkan seorang peneliti menggali kebutuhan dasar konsumen secara kelompok diskusi sehingga dapat diketahui motif, kecenderungan pikiran dan emosi responden dari sekelompok orang yang telah ditentukan.

\section{Teknik Sampling}

Untuk tahap pebgumpulan data suatu penelitian, diperlukan proses sampling terhadap data yang dibutuhkan. Terdapat dua metode teknik sampling yang umumnya digunakan dalam penelitian yaitu metode non probabilistik dan probabilistik.

\footnotetext{
Voice of Engineering (VOE)

Voice of Engineering (VOE) memuat karakteristik teknis (Technical Reqruitment), yang merupakan gambaran produk atau jasa yang direncanakan untuk dikembangkan agar dapat memenuhi kebutuhan pelanggan. Biasanya technical reqruitment ini
}

diturunkan dari kebutuhan pada tahap 1 yaitu VOC. Karakteristik teknis dapat diartikan sebagai kumpulan keinginan terhadap suatu produk atau proses yang ditetapkan oleh organisasi yang juga menunjukan suara atau keinginan dari perusahaan selaku pembuat produk (Voice of Engineering).

Dalam VOE ini akan ditentukan nilai target spesifikasi produk yang mampu dibuat oleh perusahaan. Hubungan antara VOC dan VOE ditentukan dalam House of Quality $(\mathrm{HoQ})$ dengan bobot hubungan Kuat = 9 , Sedang $=3$, Lemah $=1$.

\section{House of Quality (HOQ)}

QFD (Quality Function Deployment) adalah suatu matriks yang sistematis, menggambarkan pendekatan yang dilakukan untuk merencanakan produk yang berkualitas (Rosnani Ginting,2013). QFD menerjemahkan selera konsumen kedalam bentuk atribut-atribut produk yang disesuaikan dengan karaakteristik teknis. Dasar dari QFD adalah TQM (Total Quality Manajement). Dalam QFD menggunakan suatu matriks yang disebut sebagai House of Quality seperti pada Gambar 2, dimana matriks ini dapat menterjemahkan keinginan konsumen kedalam karakteristik desain. Fokus utama dari QFD adalah melibatkan pelanggan pada proses pengembangan produk sedini mungkin. Langkah-langkah dalam membangun QFD (Rosnani Ginting,2013):

1. Mengidentifikasi keinginan konsumen kedalam atribut-atribut produk

Pada tahap ini akan diuji sampai sejauh mana tingkat kepuasan konsumen terhadap suatu produk.

2. Menentukan tingkat kepentingan relatif dari atribut-atribut dengan memberikan bobot persentase pada masaing-masing atribut. dengan menggunakan skala prioritas.

3. Mengevaluasi atribut-atribut dari produk pesaing, keterangan 
mengenai atribut yang diprioritaskan pesaing dikaji.

4. Membuat matriks perlawan antara atribut produk dengan karakteristik. pada tahap ini dimasukkan kedalam suatu matriks, dimana atribut diletakknvertikal pada tepi sebelah kiri, sedangkan karakteristik teknis diletakkan horisontal pada tepi atas.

5. Mengidentifikasi karakteristik teknik dan aribut produk, untuk menyatukan hubungan yang terjadi antara karakteristik teknis dan atribut, biasanya menggunakan skor, dimana skor yang tertinggi menggambarkan tingkat kemudahan yang tinggi karakteristik teknis yang paling berpengaruh pada kepuasan konsumen dan sebaliknya.

6. Mengidentifikasi interaksi yang relevan diantara karakteristik teknis, dalam matrik $\mathrm{HOQ}$, besaran diletakkan pada bagian atap.

7. Menentukan gambaran target yang ingin dicapai untuk karakteristik teknis.
Tahap implementasi pembuatan House of Quality dilakukan dengan langkah-langkah sebagai berikut:

1. Penyusunan Voice of Customer, dengan melakukan wawancara dan penyebaran kuisioner kepada konsumen untuk memperoleh atribut (suara pelanggan).

2. Penentuan tingkat kepentingan konsumen terhadap produk yang merupakan tingkatan/nilai kepentingan dari masing-masing factor yang dianggap mampu memenuhi kepuasan konsumen.

3. Evaluasi kualitas produk dibandingkan dengan produk pesaing yang kompetitif, produk competitor dalam hal ini akan menjadi produk referensi atau benchmark.

4. Penyusunan technical requirements berdasarkan voice of engineer yang merupakan kemampuan teknis yang dimiliki oleh perusahaan untuk memenuhi Customer Needs.

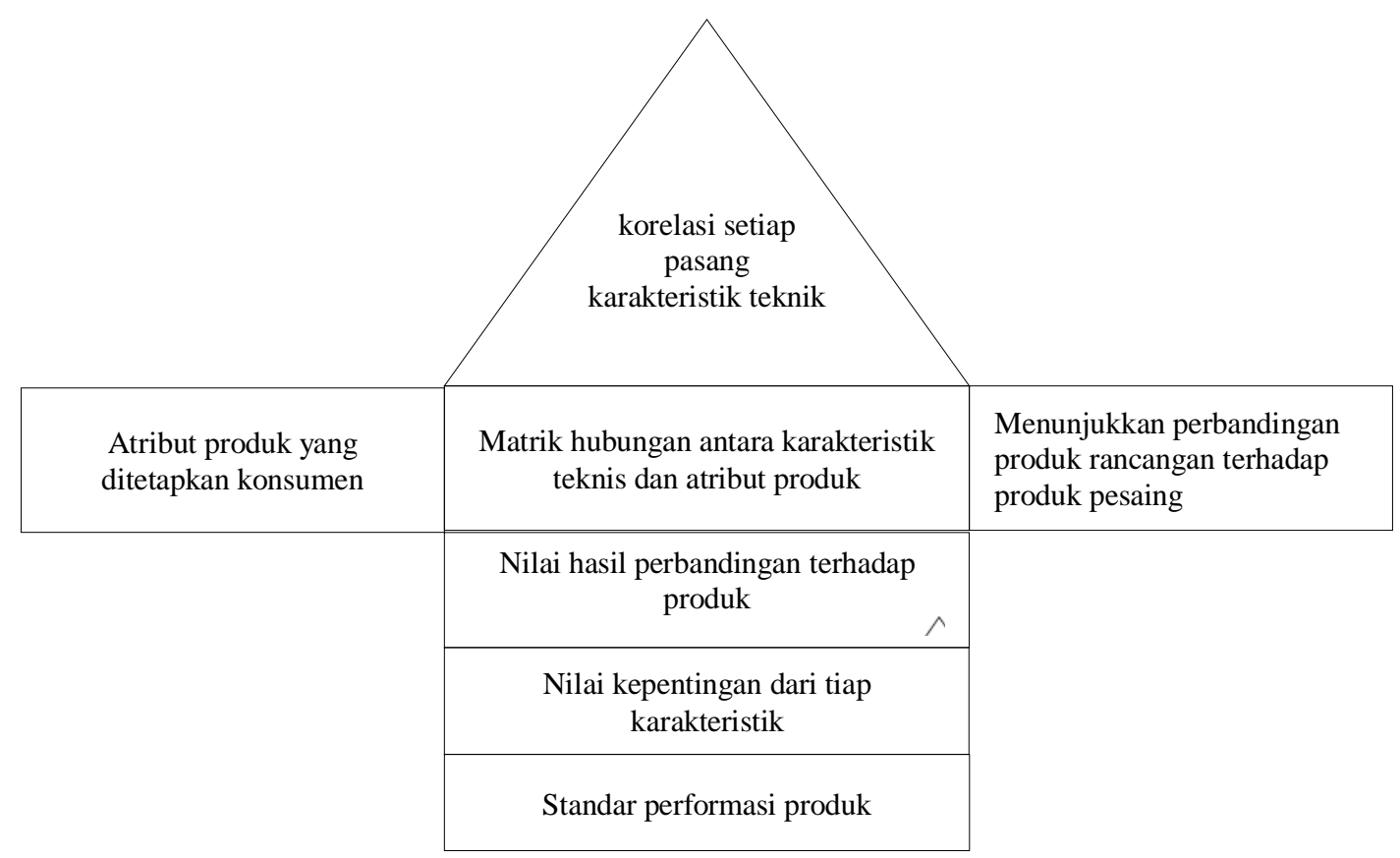

Gambar 2.House of Quality 
Tabel 1 Perbandingan antara Kajian Terdahulu

\begin{tabular}{|c|c|c|c|c|}
\hline $\begin{array}{l}\text { Nama } \\
\text { peneliti, } \\
\text { tahun }\end{array}$ & Judul & $\begin{array}{l}\text { Permasalahan yang } \\
\text { dihadapi }\end{array}$ & Alat Analisis & Hasil \\
\hline $\begin{array}{l}\text { Bayu } \\
\text { Chrisdiyanto } \\
, 2014\end{array}$ & $\begin{array}{ll}\text { Perencanaan } & \text { dan } \\
\text { Pengembangan } \\
\text { Meja Belajar Lipat } \\
\text { Multifungsi yang } \\
\text { Ergonomi dengan } \\
\text { Metode QFD }\end{array}$ & $\begin{array}{l}\text { Desain meja belajar } \\
\text { kurang memperhatikan } \\
\text { nilai ergonomi, dan lebih } \\
\text { mengutamakan desain } \\
\text { bentuk yang simple,fungsi } \\
\text { utama dari meja belajar } \\
\text { tersebut terabaikan. }\end{array}$ & $\begin{array}{l}\text { Metode } \\
\text { Quality Fuction } \\
\text { Deployment } \\
\text { (QFD) }\end{array}$ & $\begin{array}{l}\text { Menghasilkan meja } \\
\text { lipat yang ergonomi } \\
\text { dan multifungsi sesuai } \\
\text { keinginan konsumen } \\
\text { dengan } \\
\text { memperhatikan } \\
\text { antropometri tubuh } \\
\text { manusia. }\end{array}$ \\
\hline $\begin{array}{l}\text { Denny } \\
\text { Nurkertama } \\
\text { nda, dkk, } \\
2006\end{array}$ & $\begin{array}{ll}\text { Perancang } & \text { Meja } \\
\text { dan Kursi } & \text { Anak } \\
\text { Menggunakan } & \\
\text { Metode } & \text { Quality } \\
\text { Function } & \\
\text { Deployment } & \text { (QFD) } \\
\text { dengan } & \\
\text { pendekatan } & \\
\text { Antropometri } & \text { dan } \\
\text { Bentuk Fisik } & \text { Anak } \\
\end{array}$ & $\begin{array}{l}\text { Kursi dan meja yang tidak } \\
\text { sesuai ukuran tubuh anak } \\
\text { yang dapat mengakibatkan } \\
\text { anak cepat mengalami } \\
\text { kelelahan. }\end{array}$ & $\begin{array}{l}\text { Metode } \\
\text { Quality Fuction } \\
\text { Deployment } \\
\text { (QFD) dan } \\
\text { antropometri. }\end{array}$ & $\begin{array}{lr}\text { Dihasilkan rancangan } \\
\text { meja dan kursi anak } \\
\text { sesuairan dengan } \\
\text { antropometri tubuh } \\
\text { anak sehingga anak } \\
\text { tidak mudah } \\
\text { mengalami kelelahan. }\end{array}$ \\
\hline $\begin{array}{l}\text { Maduretno } \\
\text { Oktavia, } \\
2007\end{array}$ & \begin{tabular}{lr}
\multicolumn{3}{l}{ Pengembangan } \\
Produk & Kursi \\
Penderita & Patah \\
Tulang & pada \\
Aktivitas & \\
Kebelakang & \\
dengan etode & QFD \\
Ditinjau dari & spek \\
Ergonomi & \\
\end{tabular} & $\begin{array}{l}\text { Kursi roda bagi penderita } \\
\text { patah tulang, sulit } \\
\text { digunakan pada saat } \\
\text { mereka ingin kebelakang. }\end{array}$ & $\begin{array}{l}\text { Metode } \\
\text { Quality Fuction } \\
\text { Deployment } \\
\text { (QFD) }\end{array}$ & $\begin{array}{lr}\text { Dihasilkan rancangan } \\
\text { kursi roda yang sesuai } \\
\text { dengan } \quad \text { keinginan } \\
\text { konsumen } \\
\text { berdasarkan QfD Dan } \\
\text { antropometri tubuh } \\
\text { konsumen. }\end{array}$ \\
\hline
\end{tabular}

5. Penyusunan Relationship Matrix, menunjukan hubungan antara respon teknis dengan customer needs. Relasi hubungan yang terjadi dikategorikan dalam 3 jenis yaitu :

- Hubungan sangat kuat dengan skor 9

- $\quad$ Sedang dengan skor 3

- Tidak ada hubungan dengan skor 1

- Penyusunan Co-relationships, digunakan untuk mengidentifikasi hubungan antara masing-masing Technical Requirements. Jenis hubungan ini adalah :Korelasi positif kuat

- Korelasi positif lemah

- Korelasi negatif kuat

- Korekasi negatif lemah

\section{Antropometri}

Antropometri merupakan bagian dari ilmu yang mempelajari tentang dimensi tubuh manusia, pentingnya antropometri karena perlunya kesesuaian antara rancangaan yang dibuat dengan dimensi tubuh pengguna. Menurut Stevenson (1989) antropometri adalah kumpulan data numerik yang berhubungan dengan karakteristik fisik manusia, bentuk serta penerapan dari data tersebut digunakan untuk penanganan masalah desain (Purnomo, 2013).

Perbandingan kajian penelitian terdahulu dapat dilihat pada Table1. 


\section{Metode Penelitian}

Dalam upaya peningkatan kenyamanan anak saat menggunakan kursi bonceng dengan melakukan perancangan ulang kursi bonceng tersebut dengan metode Quality Fuction Deployment (EOQ) obyek yang diteliti adalah keinginan konsumen, selain itu juga menggunakan pengaplikasian metode antropometri untuk mengetahui ukuran tubuh anak usia 1 sampai 3 tahun, sehingga dapat meningkatkan kenyamanan anak.

Prosedur yang ditempuh guna mendapatkan data atau informasi dari obyek penelitian agar sesuai dengan tujuan dan efektifitas penelitian ini adalah studi kepustakaan, observasi, wawancara dan kuesioner.

Data hasil pengukuran antropometri anak usia 1-3 tahun dalam penelitian ini kemudian diolah secara statistik untuk dilakukan uji normalitas, uji kecukupan data, uji keseragaman (Zulfa, 2008). Setelah itu kuesioner mengenai keinginan pelanggan akan dianalisa menggunakan matrik $\mathrm{HOQ}$ dan QFD. Selanjutnya dilakukan perancangan spesifikasi produk kursi bonceng anak yang memperhatikan aspek keamanan, ergonomis dan sesuai dengan keinginan pelanggan.

Perancangan dimensi kursi menggunakan data antropometri dengan nilai persentil yang sesuai (Suhardi, 2015). Persentil adalah nilai yang menunjukkan prosentase tertentu dari orang yang memiliki ukuran pada atau di bawah nilai tersebut.

\section{Hasil dan Pembahasan}

\section{Uji Validitas dan Reabilitas Kuisoner} Tertutup

1. Uji validitas data

a. Uji validitas data kuisoner tertutup untuk ekspektasi pelanggan dapat dilihat dalam tabel 2.

Tabel 2 Uji Validitas Kuisoner Tertutup untuk Ekspektasi Pelanggan

\begin{tabular}{|l|l|l|}
\hline r hitung & r tabel & Hasil \\
\hline 0,378 & 0,361 & Valid \\
\hline 0,326 & 0,361 & Valid \\
\hline
\end{tabular}

\begin{tabular}{|l|l|l|}
\hline $\mathbf{r}$ hitung & $\mathbf{r}$ tabel & Hasil \\
\hline 0,386 & 0,361 & Valid \\
\hline 0,447 & 0,361 & Valid \\
\hline 0,759 & 0,361 & Valid \\
\hline 0,833 & 0,361 & Valid \\
\hline 0,869 & 0,361 & Valid \\
\hline 0,368 & 0,361 & Valid \\
\hline 0,993 & 0,361 & Valid \\
\hline 0,395 & 0,361 & Valid \\
\hline
\end{tabular}

Sumber: Data primer yang Diperoleh (2017)

Dari hasil tabel diatas dapat diketahui bahwa hasil kuisoner tertutup ekspektasi pelanggan dapat diketahui bahwa $r$ hitung lebih besar dari $r$ tabel maka data dikatakan valid, dengan signifikasi 0,05 .

b. Uji validitas data kuisoner tertutup untuk produk unggulan dapat dilihat pada tabel 3

Tabel 3 Uji Validitas Kuisoner tertutup untuk produk unggulan

\begin{tabular}{|l|l|l|}
\hline r Hitung & r Tabel & Hasil \\
\hline 0,585 & 0,361 & Valid \\
\hline 0,461 & 0,361 & Valid \\
\hline 0,464 & 0,361 & Valid \\
\hline 0,621 & 0,361 & Valid \\
\hline 0,851 & 0,361 & Valid \\
\hline 0,533 & 0,361 & Valid \\
\hline 0,644 & 0,361 & Valid \\
\hline 0,792 & 0,361 & Valid \\
\hline 0,944 & 0,361 & Valid \\
\hline 0,764 & 0,361 & Valid \\
\hline
\end{tabular}

Sumber: Data primer yang Diperoleh (2017)

Dari hasil tabel diatas dapat diketahui bahwa hasil kuisoner tertutup untuk produk unggulan dapat diketahui bahwa $r$ hitung lebih besar dari $r$ tabel maka data dikatakan valid, dengan signifikasi 0,05 .

c. Uji validitas data kuisoner tertutup untuk produk pesaing dapat dilihat pada tabel 4 . 
Tabel 4. Uji Validitas Kuisoner tertutup untuk produk Pesaing

\begin{tabular}{|l|l|l|}
\hline r Hitung & $\begin{array}{l}\mathbf{r} \\
\text { Tabel }\end{array}$ & Hasil \\
\hline 0,395 & 0,361 & Valid \\
\hline 0,547 & 0,361 & Validz \\
\hline 0,947 & 0,361 & Valid \\
\hline 0,631 & 0,361 & Valid \\
\hline 0,920 & 0,361 & Valid \\
\hline 0,552 & 0,361 & Valid \\
\hline 0,645 & 0,361 & Valid \\
\hline 0,823 & 0,361 & Valid \\
\hline 0,616 & 0,361 & Valid \\
\hline 0,823 & 0,361 & Valid \\
\hline
\end{tabular}

Sumber: Data primer yang Diperoleh (2017)

Dari hasil tabel diatas dapat diketahui bahwa hasil kuisoner tertutup produk pesaing dapat diketahui bahwa $r$ hitung lebih besar dari $r$ tabel maka data dikatakan valid, dengan signifikasi 0,05.

2. Uji Reabilitas

a. Uji reabilitas data kuisoner tertutup untuk ekspektasi pelanggan dapat dilihat dalam tabel 5 .

Tabel 5. Uji Reabilitas Kuisoner Tertutup untuk Ekspektasi Pelanggan

\begin{tabular}{|l|l|l|}
\hline r hitung & $\mathbf{r}$ tabel & Hasil \\
\hline 0,453 & 0,361 & Valid \\
\hline 0,464 & 0,361 & Valid \\
\hline 0,419 & 0,361 & Valid \\
\hline 0,459 & 0,361 & Valid \\
\hline 0,422 & 0,361 & Valid \\
\hline 0,711 & 0,361 & Valid \\
\hline 0,362 & 0,361 & Valid \\
\hline 0,369 & 0,361 & Valid \\
\hline 0,373 & 0,361 & Valid \\
\hline 0,363 & 0,361 & Valid \\
\hline
\end{tabular}

Sumber: Data primer yang Diperoleh (2017)

Dari hasil uji reabilitas kuisoner tertutup untuk ekspektasi pelanggan menunjukkan bahwa $r$ hitung lebih besar dari $r$ tabel maka data tersebut reliabel, dengan signitifaksi sebesar 0,05. b. Uji reabilitas kuisoner tertutup untuk kelompok data produk unggulan dapat dilihat pada tabel 6 .

Tabel 6. uji Reabilitas Kuisoner Tertutup untuk Produk Unggulan

\begin{tabular}{|l|l|l|}
\hline r Hitung & $\mathbf{r}$ Tabel & Hasil \\
\hline 0,446 & 0,361 & Valid \\
\hline 0,440 & 0,361 & Valid \\
\hline 0,345 & 0,361 & Valid \\
\hline 0,383 & 0,361 & Valid \\
\hline 0,475 & 0,361 & Valid \\
\hline 0,573 & 0,361 & Valid \\
\hline 0,560 & 0,361 & Valid \\
\hline 0,497 & 0,361 & Valid \\
\hline 0,673 & 0,361 & Valid \\
\hline 0,615 & 0,361 & Valid \\
\hline
\end{tabular}

Sumber: Data primer yang Diperoleh (2017)

Dari hasil uji reabilitas kuisoner tertutup untuk produk unggulan menunjukkan bahwa $r$ hitung lebih besar dari $r$ tabel maka data tersebut reliabel, dengan signitifaksi sebesar 0,05.

c. Uji reabilitas kuisoner tertutup untuk kelompok data pesaing dapat dilihat dari tabel 7 .

Tabel 7. Uji Reabilitas Kuisoner Tertutup untuk Produk Pesaing

\begin{tabular}{|l|l|l|}
\hline r Hitung & $\begin{array}{l}\mathbf{r} \\
\text { Tabel }\end{array}$ & Hasil \\
\hline 0,518 & 0,361 & Valid \\
\hline 0,713 & 0,361 & Valid \\
\hline 0,762 & 0,361 & Valid \\
\hline 0,508 & 0,361 & Valid \\
\hline 0,454 & 0,361 & Valid \\
\hline 0,523 & 0,361 & Valid \\
\hline 0,363 & 0,361 & Valid \\
\hline 0,571 & 0,361 & Valid \\
\hline 0,482 & 0,361 & Valid \\
\hline 0,672 & 0,361 & Valid \\
\hline
\end{tabular}

Sumber: Data primer yang Diperoleh (2017)

Dari hasil uji reabilitas kuisoner tertutup untuk produk pesaing menunjukkan bahwa $r$ hitung lebih besar dari $r$ tabel maka data tersebut reliabel, 
dengan signitifaksi sebesar 0,05. Seluruh perhitungan uji reabilitas dapat dilihat pada lampiran 1.

Selain itu bahan yang akan digunakan dalam perancangan adalahrotan, karena harga rotan lebih ekonomis dan berat yang lebih ringan dibanding bahan lainya seperti alumunium dan stainless. Selain itu bahan rotan tidak mudah merusak kendaraaan, jika tergores di bagian sambungan kerangka serta tidak menimbulkan luka dan lebih aman diaplikasikan untuk anak-anak.

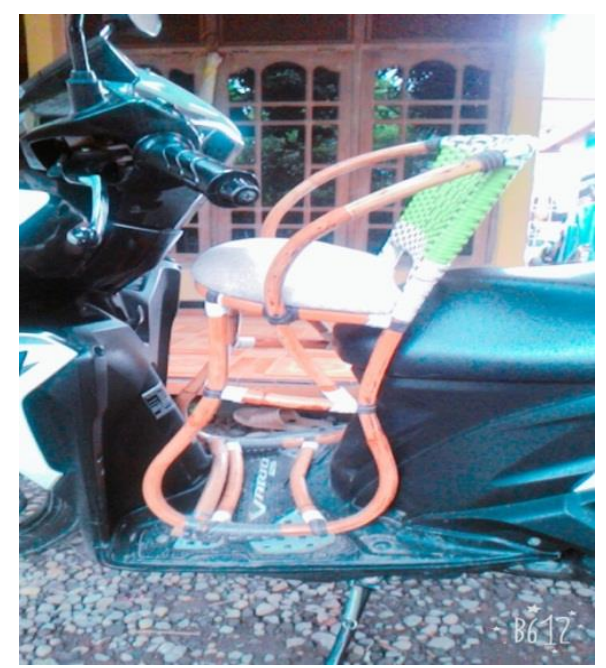

Gambar 3. Kursi Bonceng Unggulan Harga : Rp. 120.000,00

Sumber: Data Primer Yang Diperoleh (2017)

\section{VOC dan Peringkatnya}

Perbandingan Spesifikasi kursi bonceng dapat dilihat pada Tabel 8 .

Hasil rekapitulasi kuisioner berdasarkan tingkat kepentingan, dapat dilihat pada Tabel 9 Sedangkan Tingkat Kepuasan Pelanggan Terhadap Produk Unggulan dan produk pesaingdan planning matrix dapat dilihat pada table 10, Tabel 11 dan Tabel 12.

Penentuan tingkat kepuasan konsumen (Husein Umar, 2005) dilakukan dengan menghitung nilai masing-masing jawaban di setiap pertanyaan disbanding dengan jumlah responden

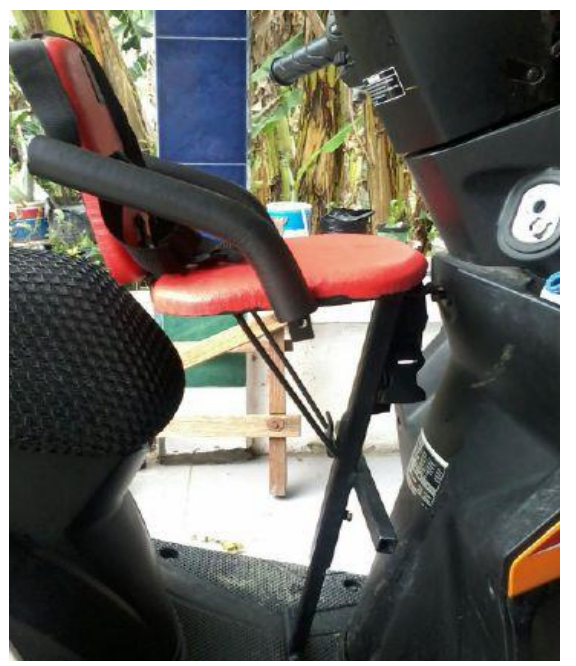

Gambar 4. Kursi Bonceng Pesaing Harga : Rp. 180.000,00 
Tabel 8. Spesifikasi Kursi Bonceng Unggulan dan Pesaing

\begin{tabular}{|l|l|l|}
\hline Komponen & Kursi Bonceng Unggulan & Kursi Bonceng Pesaing \\
\hline Jok atau dudukan & Busa dan kain & Busa dan Kulit sintesis \\
\hline Sandaran & Rotan sintes & Busa dan kulit sintesis \\
\hline Pegangan Tangan & Rotan & Besi dan Busa \\
\hline Kaki & Rotan & Besi \\
\hline Sabuk Pengaman & Belum Ada & Polyester \\
\hline
\end{tabular}

Sumber: Data Primer Yang Diperoleh (20

Tabel 9. Rekapitulasi Kuisioner Berdasarkan Tingkat Kepentingan (TK)

\begin{tabular}{|l|l|l|l|l|l|l|l|}
\hline \multirow{2}{*}{ No } & \multirow{2}{*}{ Customer Needs } & \multicolumn{2}{|l}{ Skala } & \multirow{2}{*}{ TK } \\
\cline { 2 - 7 } $\mathbf{1}$ & $\begin{array}{l}\text { Kursi bonceng anak yang sesuai bentuk sepeda } \\
\text { motormatic }\end{array}$ & 0 & 0 & 2 & 15 & 13 & 4,37 \\
\hline $\mathbf{2}$ & Kursi bonceng anak yang aman bagi pemakai & 0 & 0 & 1 & 14 & 15 & 4,47 \\
\hline $\mathbf{3}$ & Kursi bonceng anak yang nyaman bagi pemakai & 0 & 0 & 2 & 14 & 14 & 4,40 \\
\hline $\mathbf{4}$ & $\begin{array}{l}\text { Kursi bonceng anak yang memiliki sandaran dan } \\
\text { jok yang terbuat dari bahan yang nyaman }\end{array}$ & 0 & 1 & 3 & 20 & 6 & 4,03 \\
\hline $\mathbf{5}$ & $\begin{array}{l}\text { Kursi bonceng anak yang terbuat dari bahan yang } \\
\text { aman }\end{array}$ & 0 & 2 & 5 & 14 & 9 & 4,00 \\
\hline $\mathbf{6}$ & $\begin{array}{l}\text { Kursi bonceng anak yang memiliki desain yang } \\
\text { menarik }\end{array}$ & 0 & 2 & 9 & 11 & 8 & 3,83 \\
\hline $\mathbf{7}$ & $\begin{array}{l}\text { Kursi bonceng anak yang dilengkapi dengan sabuk } \\
\text { pengaman, pijakan kaki }\end{array}$ & 0 & 2 & 16 & 5 & 7 & 3,60 \\
\hline $\mathbf{8}$ & Kursi bonceng anak yang mudah digunakan & 0 & 0 & 0 & 19 & 11 & 4,33 \\
\hline $\mathbf{9}$ & Kursi bonceng anak yang harganya terjangkau & 0 & 3 & 3 & 9 & 15 & 4,20 \\
\hline $\mathbf{1 0}$ & $\begin{array}{l}\text { Kursi bonceng anak yang memiliki rangka yang } \\
\text { kuat }\end{array}$ & 0 & 0 & 2 & 10 & 18 & 4,53 \\
\hline
\end{tabular}

Sumber: Data primer yang Diperoleh (2017)

Nilai tingkat kepuasan diatas dicari menggunakan rumus sebagai berikut: $\mathrm{TK}=\underline{(\mathrm{N} 1 \times 1)+(\mathrm{N} 2 \times 2)+(\mathrm{N} 3 \times 3)+(\mathrm{N} 4 \times 4)+(\mathrm{N} 5 \times 5)}$ (Jumlah responden)

Keterangan:

N1 = Jumlah responden dengan jawaban "sangat tidak memuaskan"

N2 = Jumlah responden dengan jawaban "tidak memuaskan"

N3 = Jumlah responden dengan jawaban "cukup"

$\mathrm{N} 4$ = Jumlah responden dengan jawaban "memuaskan"

N5 = Jumlah responden dengan jawaban "sangat memuaskan"

Tabel 10. Rekapitulasi Kuisioner Berdasarkan Tingkat Kepuasan Produk unggulan

\begin{tabular}{|c|c|c|c|c|c|c|c|}
\hline \multirow[t]{3}{*}{ No. } & \multirow{3}{*}{ Customer Needs } & \multicolumn{5}{|c|}{$\begin{array}{l}\text { SKALA } \\
\text { PENGUKURAN }\end{array}$} & \multirow{3}{*}{$\begin{array}{l}\text { Nilai } \\
\text { Kepuasan }\end{array}$} \\
\hline & & \multicolumn{5}{|c|}{ Produk Unggulan } & \\
\hline & & 1 & 2 & 3 & 4 & 5 & \\
\hline 1 & $\begin{array}{l}\text { Kursi bonceng anak yang sesuai bentuk sepeda } \\
\text { motormatic }\end{array}$ & 0 & 1 & 13 & 12 & 4 & 3,63 \\
\hline
\end{tabular}




\begin{tabular}{|c|c|c|c|c|c|c|c|}
\hline \multirow[t]{3}{*}{ No. } & \multirow[t]{3}{*}{ Customer Needs } & \multicolumn{5}{|c|}{$\begin{array}{l}\text { SKALA } \\
\text { PENGUKURAN }\end{array}$} & \multirow{3}{*}{$\begin{array}{l}\text { Nilai } \\
\text { Kepuasan }\end{array}$} \\
\hline & & \multicolumn{5}{|c|}{\begin{tabular}{|l|} 
Produk Unggulan \\
\end{tabular}} & \\
\hline & & 1 & 2 & 3 & 4 & 5 & \\
\hline 2 & Kursi bonceng anak yang aman bagi pemakai & 0 & 2 & 9 & 19 & 0 & 3,57 \\
\hline 3 & Kursi bonceng anak yang nyaman bagi pemakai & 0 & 2 & 11 & 16 & 1 & 3,53 \\
\hline 4 & $\begin{array}{l}\text { Kursi bonceng anak yang memiliki sandaran dan } \\
\text { jok yang terbuat dari bahan yang nyaman }\end{array}$ & 1 & 6 & 15 & 8 & 0 & 3,00 \\
\hline 5 & Kursi bonceng terbuat dari bahan yang aman & 0 & 3 & 10 & 11 & 6 & 3,67 \\
\hline 6 & Kursi bonceng memiliki desain yang menarik & 0 & 2 & 14 & 12 & 2 & 3,47 \\
\hline 7 & $\begin{array}{l}\text { Kursi bonceng anak yang dilengkapi dengan } \\
\text { pijakan kaki, sabuk pengaman }\end{array}$ & 0 & 4 & 14 & 10 & 2 & 3,33 \\
\hline 8 & Kursi bonceng yang mudah digunakan & 0 & 3 & 10 & 12 & 5 & 3,63 \\
\hline 9 & Kursi bonceng yang harganya terjangkau & 0 & 3 & 9 & 10 & 8 & 3,77 \\
\hline 10 & Kursi bonceng yang memiliki rangka yang kuat & 0 & 1 & 11 & 10 & 8 & 3,83 \\
\hline
\end{tabular}
Sumber: Data primer yang Diperoleh (2017)

Kepuasan Pelanggan Terhadap Produk Pesaing

Berikut merupakan rekapitulasi kuisioner berdasarkan tingkat kepuasan produk pesaing.

Tabel 11. Rekapitulasi Kuisioner Berdasarkan Tingkat Kepuasan Produk Pesaing

\begin{tabular}{|c|c|c|c|c|c|c|c|}
\hline \multirow[t]{3}{*}{ No } & \multirow{3}{*}{ Customer Needs } & \multicolumn{5}{|c|}{ SKALA PENGUKURAN } & \multirow{3}{*}{$\begin{array}{l}\text { Nilai } \\
\text { kepuasan }\end{array}$} \\
\hline & & \multicolumn{5}{|c|}{ Produk Pesaing } & \\
\hline & & 1 & 2 & 3 & 4 & 5 & \\
\hline 1 & $\begin{array}{l}\text { Kursi bonceng anak yang sesuai bentuk } \\
\text { sepeda motormatic }\end{array}$ & 0 & 8 & 18 & 4 & 0 & 2,87 \\
\hline 2 & Kursi bonceng anak aman bagi pemakai & 0 & 4 & 15 & 10 & 1 & 3,27 \\
\hline 3 & Kursi bonceng anak nyaman bagi pemakai & 0 & 6 & 6 & 14 & 4 & 3,53 \\
\hline 4 & $\begin{array}{l}\text { Kursi bonceng anak yang memiliki sandaran } \\
\text { dan jok yang terbuat dari bahan yang aman }\end{array}$ & 0 & 2 & 9 & 15 & 4 & 3,70 \\
\hline 5 & $\begin{array}{l}\text { Kursi bonceng anak yang terbuat dari bahan } \\
\text { yang aman }\end{array}$ & 0 & 5 & 15 & 5 & 5 & 3,33 \\
\hline 6 & $\begin{array}{l}\text { Kursi bonceng anak yang memiliki desain } \\
\text { yang menarik }\end{array}$ & 0 & 6 & 20 & 2 & 2 & 3,00 \\
\hline 7 & $\begin{array}{l}\text { Kursi bonceng anak yang dilengkapi dengan } \\
\text { pijakan kaki, sabuk pengaman }\end{array}$ & 0 & 8 & 11 & 11 & 0 & 3,10 \\
\hline 8 & Kursi bonceng anak yang mudah digunakan & 0 & 3 & 8 & 13 & 6 & 3,73 \\
\hline 9 & Kursi bonceng anak harganya terjangkau & 1 & 4 & 18 & 6 & 1 & 3,07 \\
\hline 10 & Kursi bonceng anak memiliki rangka kuat & 0 & 1 & 8 & 9 & 12 & 4,07 \\
\hline
\end{tabular}


Tabel 12.Rekapitulasi Kuisioner Berdasarkan Planning Matrix

\begin{tabular}{|c|c|c|c|c|c|c|c|c|c|c|}
\hline NO & 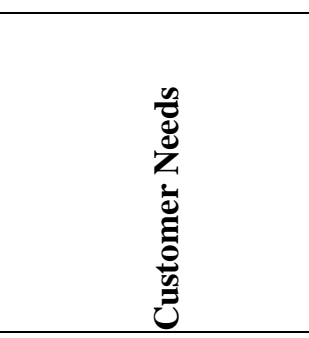 & 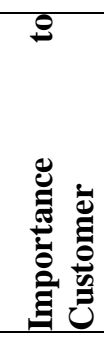 & 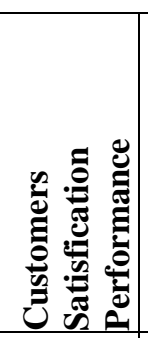 & 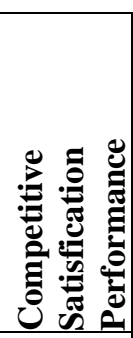 &  & 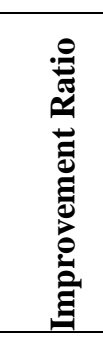 & $\begin{array}{l}\vec{\Xi} \\
\dot{0} \\
\frac{\tilde{e}}{\tilde{E}} \\
\tilde{n}\end{array}$ &  & 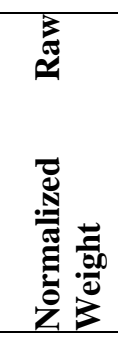 & 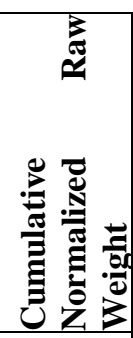 \\
\hline 1 & $\begin{array}{l}\text { Kursi bonceng anak } \\
\text { yang sesuai bentuk } \\
\text { sepeda motormatic }\end{array}$ & 4,37 & 3,63 & 2,87 & 3,63 & 1 & 1,2 & 5,24 & 0,09 & 0,09 \\
\hline 2 & $\begin{array}{l}\text { Kursi bonceng anak } \\
\text { yang aman bagi } \\
\text { pemakai }\end{array}$ & 4,47 & 3,57 & 3,27 & 3,57 & 1 & 1,5 & 6,75 & 0,12 & 0,21 \\
\hline 3 & $\begin{array}{l}\text { Kursi bonceng anak } \\
\text { yang nyaman bagi } \\
\text { pemakai }\end{array}$ & 4,40 & 3,53 & 3,53 & 3,53 & 1 & 1,2 & 5,28 & 0,09 & 0,30 \\
\hline 4 & $\begin{array}{l}\text { Kursi bonceng anak } \\
\text { yang memiliki } \\
\text { sandaran dan jok } \\
\text { yang terbuat dari } \\
\text { bahan yang aman }\end{array}$ & 4,03 & 3,00 & 3,70 & 3,70 & 1,2 & 1,5 & 7,53 & 0,13 & 0,43 \\
\hline 5 & $\begin{array}{l}\text { Kursi bonceng anak } \\
\text { yang terbuat dari } \\
\text { bahan yang aman }\end{array}$ & 4,00 & 3,67 & 3,33 & 3,67 & 1 & 1,2 & 4,88 & 0,09 & 0,51 \\
\hline 6 & $\begin{array}{l}\text { Kursi bonceng anak } \\
\text { yang memiliki } \\
\text { desain yang menarik }\end{array}$ & 3,83 & 3,47 & 3,00 & 3,47 & 1 & 1,2 & 4,60 & 0,08 & 0,59 \\
\hline 7 & $\begin{array}{lr}\text { Kursi bonceng anak } \\
\text { yang } r \text { dilengkapi } \\
\text { dengan pijakan kaki } \\
\text { dan } & \text { sabuk } \\
\text { pengaman } & \end{array}$ & 3,60 & 3,33 & 3,10 & 3,63 & 1,1 & 1,2 & 4,67 & 0,08 & 0,68 \\
\hline 8 & $\begin{array}{lr}\text { Kursi bonceng anak } \\
\text { yang } & \text { mudah } \\
\text { digunakan } & \\
\end{array}$ & 4,33 & 3,63 & 3,73 & 3,73 & 1 & 1,5 & 6,71 & 0,12 & 0,79 \\
\hline 9 & $\begin{array}{l}\text { Kursi bonceng anak } \\
\text { yang harganya } \\
\text { terjangkau }\end{array}$ & 4,20 & 3,77 & 3,07 & 3,77 & 1 & 1,5 & 6,30 & 0,11 & 0,90 \\
\hline 10 & $\begin{array}{l}\text { Kursi bonceng anak } \\
\text { yang memiliki } \\
\text { rangka yang kuat }\end{array}$ & 4,53 & 3,83 & 4,07 & 3,83 & 1 & 1,2 & 5,44 & 0,10 & 1,00 \\
\hline \multicolumn{2}{|c|}{ Jumlah } & 41,91 & 35,43 & 33,67 & 36,53 & 10,35 & 13,20 & 57,43 & 1,00 & 5,51 \\
\hline
\end{tabular}

Sumber: Data primer yang Diperoleh (2017) 


\section{Analisa HOQ}

Gambar diagram matrix $\mathrm{HOQ}$ dapat dilihat pada Tabel 13.

1. Analisa Tingkat Kepentingan

Berdasarkan VOC yang telah disebar dan isi oleh responden, 3 peringkat tertinggi

kami munculkan dan dipertimbangkan lebih untuk pengembangan demi memenuhi kebutuhan konsumen dan menarik untuk daya jual lebih tinggi

a. Tingkat kepentingan nilai kurang dari 4 :

1) Kursi bonceng anak yang memiliki desain yang menarik

2) Kursi bonceng anak yang dilengkapi dengan pijakan kaki, sabuk pengaman.

b. Tingkat kepentingan nilai 4 - 5:

1) Kursi bonceng anak yang sesuai bentuk sepeda motor matic

2) Kursi bonceng anak yang aman bagi pemakai

3) Kursi bonceng anak yang nyaman bagi pemakai

4) Kursi bonceng anak yang memiliki sandaran dan jok yang terbuat dari bahan yang aman

5) Kursi bonceng anak yang terbuat dari bahan yang aman

6) Kursi bonceng anak yang mudah digunakan

7) Kursi bonceng anak yang harganya terjangkau

8) Kursi bonceng anak yang memiliki rangka yang kuat

2. Analisa Kebutuhan Teknik

a. Korelasi VOE

1) Hubungan Positif Kuat

Adapun hubungan positif kuat dari korelasi VOE sebagai berikut:

- Bahan baku kerangka kursi bonceng adalah rotan.

- Bahan baku busa memiliki ketebalan $4 \quad \mathrm{~cm}$ sangatberhubungan kuat dengan harga kursi bonceng

- Sandaran dan jok terbuat dari busa memiliki hubungan yang kuat dengan ketebalan busa.
- Bahan baku sabuk terbuat dari polyester sangat berhubungan kuat dengan harga kursi bonceng.

2) Hubungan Positif Sedang

- Penambahan sabuk pengaman berhubungan positif sedang dengan harga kursi bonceng

- Sandaran dan jok terbuat dari busa berhubunngan sedang dengan harga kursi bonceng.

- Memiliki ketebalan busa 4 $\mathrm{cm}$, berhubungan positif sedang dengan berat kursi bonceng

- Sesuai dengan antropometri tubuh anak memiliki hubungan positif sedang dengan penambahan sabuk pengaman.

- Sabuk pengaman terbuat dari bahan polyester memilki hubungan yang positif sedang dengan bentuk yang menarik.

3) Hubungan Negatif Sedang

- Memiliki bentuk dan warna menarik memiliki hubungan negatif sedang dengan harga, bahan dari rotan, sandaran dan jok terbuat dari busa serta sesuai dengan antropometri tubuh manusia.

- Kursi bonceng yang memiliki berat $2 \mathrm{~kg}$ memiliki hubungan negatif sedang dengan bahan sabuk pengaman dari polyester.

- Penambahan sabuk pengaman memiliki hubungan positif sedang dengan bentuk dan warna menarik dan bahan baku sabuk pengaman dari polyester.

- Ketebalan busa sebesar 4 $\mathrm{cm}$ berhubungan negatif sedang dengan bentuk kursi bonceng. 


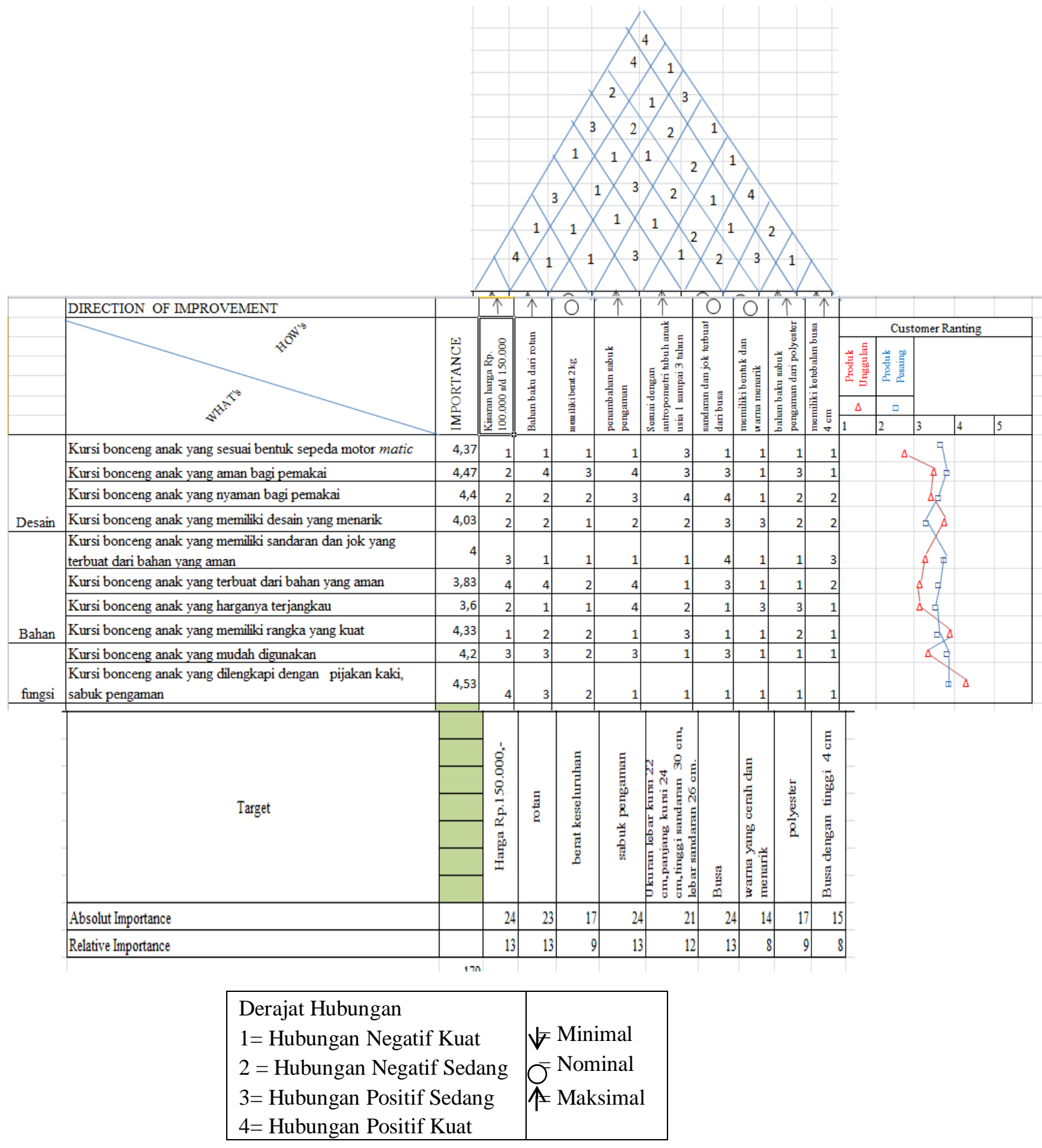

Gambar 13. House of Quality

Sumber: Data primer yang Diperoleh (2017) 
4) Hubungan Negatif Kuat

- Harga memiliki hubungan negatif kuat dengan berat kursi bonceng serta antropometri tubuh anak.

- Bahan baku kerangka dari rotan tidak memiliki keterkaitan dengan penambahan sabuk pengaman, antropometri tubuh anak, sandaran dan jok dari busa, bahan baku sabuk pengaman, serta ketebalan busa.

- Penambahan sabuk pengaman berhubungan negatif kuat dengan bahan baku sandaran dan jok serta ketebalan busa.

- Antropometri tubuh anak memiliki hubungan negatif kuat dengan bahan baku sandaran dan jok, bahan baku sabuk pengaman serta ketebalan busa.

- Bahan baku sandaran dan jok terbuat dari busa memiiki hubunhgan negatif kuat dengan bahan baku sabuk pengaman.

- Bahan baku sabuk pengaman tidak terkait dengan ketebalan busa.

3. Analisa Direction Of Improvement

a. Maksimal

Nilai positif diberi tanda panah ke atas untuk menunjukan produk yang lebih dikembangkan salah satunya seperti berikut ini:

- Kisaran harga kursi bonceng anak perlu dinaikkan karena setiap tahun harga bahan-bahan untuk membuat kursi bonceng setiap tahun akan mengalami kenaikan.

- Bahan baku rotan perlu ditingkatkan kualitasnya untuk keamanan pengguna.

- Penambahan sabuk pengaman perlu dilakukan untuk memberi keamanan saat menggunakan kursi bonceng tersebut.

- Kursi bonceng yang sesuai dengan antropometri tubuh manusia sangat diperlukan untuk merancang kursi bonceng yang ergonomi.

- Bahan baku sabuk pengaman perlu diperhatikan untuk keamanan dan kenyamanan pengguna kursi bonceng.

- Ketebalan busa perlu diperhatikan untuk kenyamanan anak saat didudukkan dikursi bonceng tersebut.

b. Nominal

Nilai nominal diberi tanda lingkaran untuk menunjukan produk sesuai yang telah ditetapkan salah satunya seperti berikut ini:

- Berat kursi bonceng tidak dinaikkan karena jika kursi bonceng beratnya dinaikkan akan menambah beban sepeda motor.

- Sandaran dan jok tetap menggunakan busa karena bahan yang nyaman untuk membuat sandaran dan jok adalah busa.

- Untuk saat ini kursi bonceng anak sudah memiliki bentuk dan warna menarik jadi tidak perlu dilakukan perbaikan.

c. Minimum

Nilai Minimum diberi tanda panah ke bawah untuk menunjukan produk yang lebih dikembangkan salah satunya seperti berikut ini:

- Sejauh ini semua komponen akan digunakan dan dikembangkan meskipun ada beberapa yang tidak dikembangkan akan tetapi masih tetap digunakan karena sudah sesuai standard..

4. Analisa Customer Rating 
Kepuasan pelanggan terhadap produk unggulan terhadap produk pesaing untuk:

- Harga kursi bonceng anak yang terjangkau nilai kepuasan produk unggulan sebesar 3.77 , produk pesaing sebesar 3.07

- Bahan sandaran dan jok kursi bonceng nilai kepuasan produk unggulan 3 , produk pesaing sebesar 3.7

- Keamanan kursi bonceng anak nilai kepuasan produk sebesar 3.57, produk pesaing sebesar 3.27

- Kenyamanan kursi bonceng anak nilai kepuasan produk unggulan sebesar 3.53 , produk pesaing sebesar 3.53 .

- Kesesuaian bentuk kursi bonceng anak dengan sepeda motor matic nilai kepuasan 3.63, produk pesaing sebesar 2.87.

- Keamanan bahan kerangka kursi bonceng anak nilai kepuasan 3.67, produk pesaing sebesar 3.33

- Desain yang menarik nilai kepuasan produk unggulan sebesar 3.47, produk pesaing sebesar 3

- Kursi bonceng anak yang memiliki pijakan kaki dan sabuk pengaman nilai kepuasan pelanggan 3.33 , produk pesaing 3.10

- Kursi bonceng anak yang mudah digunakan nilai kepusan pelanggan nilai kepuasan pelanggan 3.63, produk unggulan 3.73

- kerangka kursi bonceng yang kuat nilai kepuasan pelanggan 3.83, produk unggulan 4.07

5. Analisa Absolute Importance

Analisa target terhadap VOC dan VOE

- Kisaran harga sepeda Rp.100.000,- yang merupakan target dari relasi antara VOE dan VOC yang jumlahnya menghasilkan 24.

- Bahan kerangka kursi bonceng anak terbuat dari rotan yang merupakan target VOE memperoleh 23 dimana hasilnya dari VOC dan VOE.

- Berat keseluruh;an aman kursi bonceng anak yang merupakan target VOE 17 dimana hasilnya dari VOC dan VOE.

- Kursi bonceng anak yang dilengkapi sabuk pengaman yang merupakan target VOE memperoleh 24 dimana hasilnya dari VOC dan VOE.

- Ukuran lebar kursi $22 \mathrm{~cm}$, panjang kursi $24 \mathrm{~cm}$, tinggi sandaran $30 \mathrm{~cm}$, lebar sandaran $26 \mathrm{~cm}$ merupakan target VOE memperoleh 21 dimana hasilnya dari VOC dan VOE

- Bahan baku sandaran dan jok terbuat dari busa merupakan target VOE memperoleh 24 dimana hasilnya dari VOC dan VOE

- Kursi bonceng dengan warna yang cerah dan menarik merupakan target VOE memperoleh 14 dimana hasilnya dari VOC dan VOE

- Sabuk pengaman dengan bahan polyester merupakan target VOE memperoleh 17 dimana hasilnya dari VOC dan VOE

- Ketebalan busa sebesar $4 \mathrm{~cm}$ merupakan target VOE memperoleh 15 dimana hasilnya dari VOC dan VOE

6. Analisa Relative Importance

Dari hasil Absolute Importance yang diperoleh yang menjadi target

- Rangking 1 adalah Rp. 150.000 yang merupakan target kisaran harga yang memperoleh $13 \%$.

- Rangking 2 adalah bahan baku dari rotan merupakan target VOE yang memperoleh $13 \%$.

- Rangking 3 adalah bahan baku sandaran dan jok dari busa merupakan target VOE yang memperoleh $13 \%$

- Ranking 4 adalah penambahan sabuk pengaman merupakan 
target VOE yang memperoleh $13 \%$

- Ranking 5 adalah Ukuran lebar kursi $22 \mathrm{~cm}$, panjang kursi 24 $\mathrm{cm}$, tinggi sandaran $30 \mathrm{~cm}$, lebar sandaran $26 \mathrm{~cm}$ merupakan target VOE yang memperoleh $12 \%$ Rangking 6 adalah berat sekedar $2 \mathrm{~kg}$ merupakan target VOE yang memperoleh $9 \%$

- Ranking 7 adalah bahan baku sabuk pengaman dari polyester merupakan target VOE yang memperoleh $9 \%$

- Ranking 8 adalah kursi bonceng anak yang mempunyai warna cerah dan menarik merupakan target VOE yang memperoleh $8 \%$

- Ranking 9 adalah ketebalan busa $4 \mathrm{~cm}$ merupakan target VOE yang memperoleh $8 \%$

\section{Analisa Pengembangan yang \\ Diusulkan}

- Kisaran harga dari produk kami ini mungkin perlu dinaikkan karena bahan-bahan pembuatan kursi bonceng kemungkinan akan naik dan juga biaya tenaga kerja yang setiap tahunnya mengalami kenaikan.

- Sandaran dan jok harus menggunakan bahan baku busa karena bahan buka dapat memberi kenyamanan saat duduk.

- Kursi bonceng anak perlu ditambahkan sabuk pengaman agar anak menjadi lebih aman saat didudukkan dikursi tersebut.

- Bahan kerangka kursi bonceng dari rotan karena bahan ini lebih aman jika diaplikasikan untuk anak-anak dan juga untuk sepeda motor matic

- Ukuran lebar kursi $22 \mathrm{~cm}$, panjang kursi $24 \mathrm{~cm}$, tinggi sandaran $30 \mathrm{~cm}$, lebar sandaran $26 \mathrm{~cm}$ dan tinggi kaki kursi bonceng sesuai dengan tinggi kursi produk yang sudah ada.
- Ketebalan busa $4 \mathrm{~cm}$ agar nyaman digunakan.

- Bahan baku sabuk pengaman dari polyester karena bahan ini aman digunakan.

- Pengait sabuk pengaman dapat diatur sesuai tebal tubuh anak.

- Untuk anak dengan berat badan 7 sampai $14 \mathrm{~kg}$.

\section{Konsep Yang Terpilih}

Konsep yang terpilih dan gambar berdasar metode QFD dan Antropometri dapat dilihat pada gambar 14 .



\section{Gambar 14. Gambar rancangan kursi}

\section{KESIMPULAN}

1. Dalam mengembangkan suatu produk, hal yang paling penting adalah mengutamakan tingkat kepuasan terhadap costumer needs sehingga produk yang dikembangkan dapat laku dipasaran.

2. Dalam metode QFD, untuk membuat menyusun konsep produk yang akan dikembangkan sesuai dengan kebutuhan konsumen maka dibutuhkan House of Quality (HOQ) Konsep perancangan kursi bonceng yang dikembangkan antara lain penambahan sabuk pengaman , menggunakan konsep antropometri tubuh manusia 
3. Hasil analisa ergonomis dari produk kursi bonceng anak dengan menggunakan perhitungan antropometri adalah:
a. Tinggi sandaran kursi bonceng $30 \mathrm{~cm}$.
b. Lebar sandaran kursi bonceng anak $26 \mathrm{~cm}$.
c. Panjang dudukan kursi bonceng anak $24 \mathrm{~cm}$.
d. Lebar tempat duduk kursi bonceng anak $22 \mathrm{~cm}$.

\section{DAFTAR PUSTAKA}

Chrisdiyanto, Bayu. 2014. Perancangan dan Pengembangan Meja Belajar Lipat Multi Fungsi Yang Ergonomis Menggunakan Metode QFD. Surakarta Tugas Akhir Mahasiswa Teknik Industri Universitas Muhammadiyah.

Cohen. 1995, Quality Fuction Deployment: How to Make QFD Work for You, AddisonWesley Publishing Co., Massachusetts.

Ginting, Rosnani. 2013. Perencanaan Produk. Yogyakarta, Graha IImu. Nurkertamanda, Denny, dkk. 2006. Perancangan Meja dan Kursi Anak Menggunakan Metode Quality Function Deployment (QFD) dengan Pendekatan antropometri dan Bentuk Fisik Anak. Jurnal Teknik Industri Universitas Diponegoro Vol.1, Hal 10-17.

Oktavia, Maduretno. 2007. Pengembangan Produk Kursi Penderita Patah Tulang pada Aktivitas Kebelakang Menggunakan Metode QFD Ditinjau dari Aspek Ergonomi.

Surakarta. Tugas Akhir Mahasiswa Tenik Industri Universitas Muhammadiyah Surakarta.

Purnomo, Hari. 2013. Antropometri dan Aplikasinya. Yogyakarta: Graha IImu.
Suhardi, Bambang. 2015. Perancangan Sistem Kerja. Surakarta: UPT UNS Press

Umar, Husein. 2005. Riset Pemasaran dan Perilaku Konsumen. Jakarta : Gramedia Pustaka Utama.

Zulfa,Muhammad Choiru. 2008. Perbaikan Sistem Kerja dan Perancangan Fasilitas Kerja Yang Ergonomis Pada Stasiun Kerja Pengecatan. Yogyakarta Tugas Akhir Mahasiswa Teknik Industri Universitas Ahmad Dahlan 